\title{
A fundação de Bracara Augusta no contexto da política de Augusto. Urbanismo e povoamento rural $^{1}$
}

\author{
Manuela MARTINS \\ Universidade do Minho \\ mmmartins@uaum.uminho.pt \\ Helena CARvalHo \\ Universidade do Minho \\ hcarvalho@uaum.uminho.pt
}

\section{RESUMO}

Este trabalho pretende analisar o processo de fundação de Bracara Augusta relacionado com a estruturação do espaço urbano e com a reorganização do território rural, usando para o efeito o vasto acervo de dados fornecidos pela arqueologia das últimas décadas. Para além da análise do contexto pré-romano, serão analisados os dados disponíveis sobre a malha urbana fundacional, bem como aqueles que se articulam com a reorganização do povoamento no território envolvente da cidade. Pretende-se igualmente refletir sobre o papel desempenhado por Bracara Augusta na evolução das comunidades indígenas da região bracarense, decorrente da sua integração no Império e da reorganização da Hispânia empreendida por Augusto.

Palavras chave: Bracara Augusta. Urbanismo. Povoamento. Cadastro romano.

\section{Bracara Augusta Foundation in the Context of Augustus' Policy. Urbanism and Rural Settlement}

\begin{abstract}
This paper aims to discuss the process of foundation of Bracara Augusta related to the structuring of the urban space and the reorganization of the countryside using the vast amount of data provided by archaeology in the last decades. Beyond the analysis of the preRoman context the data available on the foundational urban grid as well as the one articulated with the changes in the settlement patterns in the surrounding territory of the city will be analysed. It is also intended to reflect on the role played by Bracara Augusta in the evolution of the indigenous communities of Braga region after its integration into the Empire and the reorganization of Hispania undertaken by Augustus.
\end{abstract}

Key Words: Bracara Augusta. Urbanism. Settlement. Roman cadastre.

Sumario: 1. Introdução.2. Antecedentes e contexto fundacional de Bracara Augusta. 3. Urbanismo. 4. Povoamento e organização do território. 5. Considerações finais.

1 Este trabalho foi realizado no âmbito do Projeto PTDC/HIS-ARQ/121136/2010, financiado pela FCT e pelo Programa COMPETE. 


\section{Introdução}

O objetivo deste trabalho centra-se na análise do processo de fundação de Bracara Augusta, quer no âmbito da estruturação do espaço urbano, quer do espaço rural, usando para o efeito o vasto acervo de dados facultados pela arqueologia das últimas décadas.

Para além da discussão do contexto fundacional e da valorização dos dados disponíveis sobre o urbanismo serão analisados os dados relativos ao povoamento e à organização do território envolvente. Pretende-se igualmente refletir sobre o papel desempenhado pela cidade de Bracara Augusta na evolução das comunidades indígenas da região bracarense, decorrente da sua integração no Império e da reorganização da Hispânia empreendida por Augusto.

A uma progressiva acumulação de vestígios resultantes de várias intervenções arqueológicas, realizadas desde 1976 na cidade de Braga, que permitiu elaborar sucessivas propostas para o traçado da cidade romana, ${ }^{2}$ corresponde um não menos significativo acervo de dados reportáveis ao seu território, que resultam de vários projetos de investigação. ${ }^{3}$ Assim, dispomos hoje de um significativo manancial de informação que permite perspetivar o quadro da fundação da cidade, em articulação com a reorganização do território, ${ }^{4}$ facto que permite ultrapassar as perspetivas mais tradicionais de análise polarizadas na dicotomia entre espaço urbano e mundo rural.

Pese embora todas as dificuldades que subsistem relativamente a um esforço de análise da realidade cidade/território, sobretudo em termos cronológicos e sociológicos, é indiscutível a importância dos resultados da arqueologia para compreender os processos relacionados com a materialização do espaço, seja ele urbano, ou rural, que nos permitem uma aproximação às novas realidades resultantes da reorganização dos territórios do NO, no tempo de Augusto. Por outro lado, cabe destacar os avanços registados na historiografia peninsular que permitem hoje percecionar o contexto de fundação das cidades augustas como processos complexos nos quais se fundem os interesses de Roma, mas, também, os das comunidades que lhes deram origem. Na verdade, os avanços da investigação relativos ao NO peninsular sugerem que cada uma das cidades fundadas por Augusto possui intrínsecas especificidades que necessitam de ser valorizadas no contexto do quadro cultural e social das regiões em que se inserem, independentemente da decisão administrativa que esteve na sua origem.

Graças às fontes históricas, epigráficas e arqueológicas disponíveis, Bracara Augusta pode ser apresentada como um caso paradigmático dos complexos processos que conduziram à criação de novas cidades, concebidas enquanto artefactos materiais e culturais, que se configuraram estratégicos na organização romana do território. A sua fundação parece igualmente constituir um processo dinâmico que corporiza longos séculos de desenvolvimento cultural na região anteriormente ocupada pelos Bracari, contribuindo para criar uma nova realidade histórica que perdurará ao longo dos séculos no protagonismo que a cidade assumirá no âmbito da Hispânia romana.

\footnotetext{
2 Martins - Delgado 1989-90; 2009, 190-191; Ribeiro 2008, 225.

3 Martins 1990; Carvalho 2008.

4 Martins - Carvalho 2010, 281-298.
} 


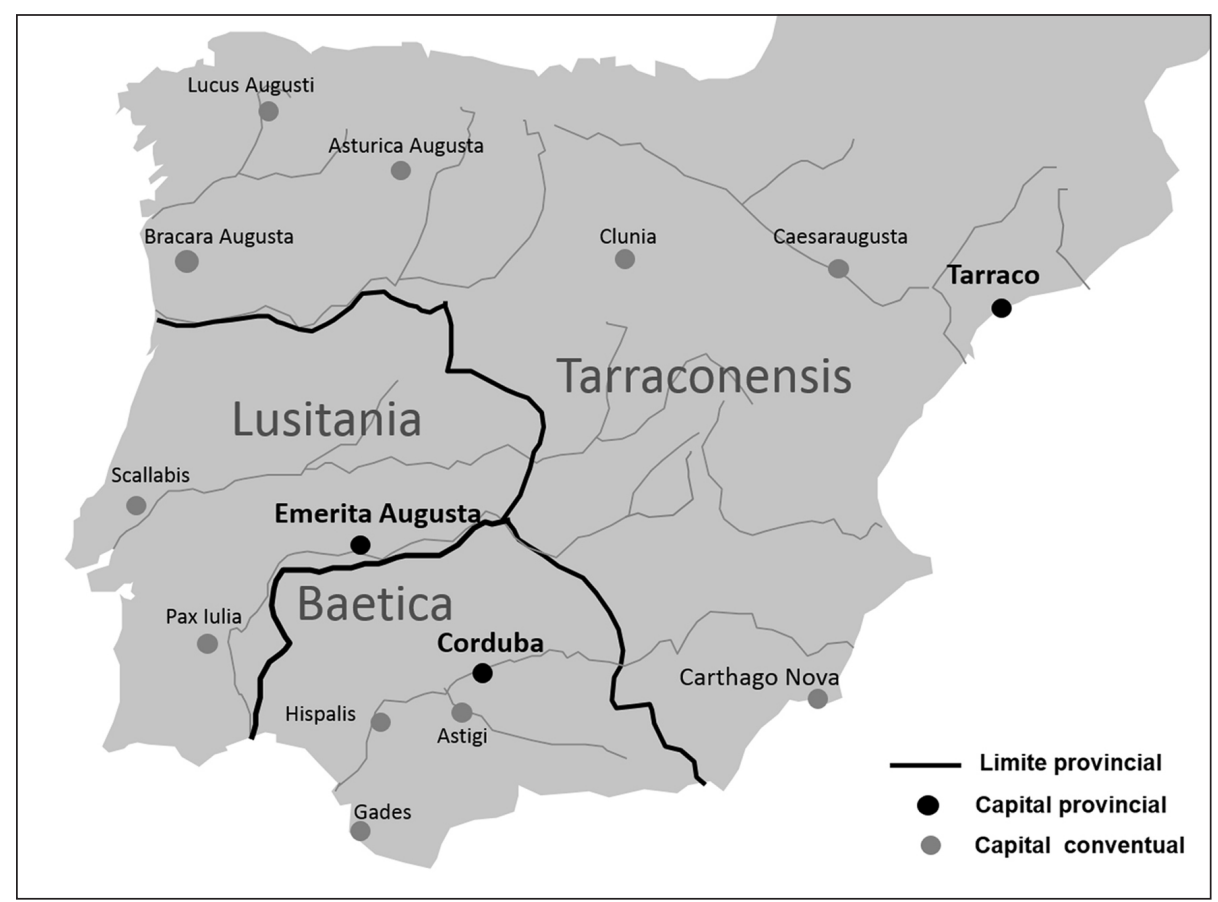

Fig. 1. Bracara Augusta no contexto administrativo da Hispânia romana.

\section{Antecedentes e contexto fundacional de Bracara Augusta}

A fundação da cidade romana de Bracara Augusta insere-se no contexto da organização política e administrativa da Hispânia, que se sucedeu ao fim das guerras cantábricas, constituindo um dos três centros urbanos criados por Augusto no NO peninsular. A data exata da fundação da cidade é ainda controversa, tal como acontece com a da reforma provincial da Hispânia, situada entre os anos 27 e 12 a.C., data da morte de Vipsânio Agripa, ${ }^{5}$ a quem Augusto teria confiado a organização dos territórios recém-conquistados, a partir de 19 a.C., ano da última batalha contra os Cântabros que encerrou o longo ciclo da conquista da Península Ibérica.

Tendo por base as referências de Plínio, ${ }^{6}$ sabemos que Agripa deverá ter integrado as regiões de Asturia e Gallaecia na província Lusitânia, que se estenderia até ao Cantábrico. No entanto, a tabula de bronze de Bembibre, datada do ano 15a.C., ${ }^{7}$ refere a existência de uma província Transduriana, que deveria incluir os territórios da Gallaecia e Asturia, demonstrando que a divisio de Agripa foi alterada, antes dos referidos territórios ficarem definitivamente incluídos na Tarraconense, em data incerta, mas seguramente posterior ao ano 15 a.C. De facto, as opiniões dividem-se

5 Bravo Castañeda 2007, 109.

6 HN III 118.

7 GraU - Hoyas 2001. 
entre aqueles que sugerem que a divisão provincial e a fixação dos respetivos limites terão sido ultimados entre 16 e 13 a.C. ${ }^{8}$ e os que apontam para ela uma data ligeiramente mais tardia, entre 12 e 7 a.C. ${ }^{9}$

As aparentes hesitações relativas ao melhor enquadramento a dar aos territórios do NO peninsular, assinaladas num curto espaço de tempo, parecem refletir o reconhecimento por parte da administração romana da especificidade da região, relativamente, quer aos territórios da Lusitânia, quer da Citerior, a qual estará na origem da muito posterior iniciativa de Caracala em criar a Província Nova Citerior Antoniana, apenas concretizada, já com Diocleciano, com a criação da província da Gallaecia. Por outro lado, as sucessivas integrações da Callaecia e Asturia em diferentes províncias parecem demonstrar que a reorganização provincial da Hispânia e, muito provavelmente também, a fundação das cidades augustas não terão constituído o resultado de um programa altamente planificado, implementado no fim das guerras cantábricas, configurando-se antes como um processo dinâmico que terá envolvido inevitáveis compromissos entre o poder romano e os representantes das comunidades indígenas, conforme aliás é sugerido pelo teor dos dados epigráficos disponíveis para o NO. ${ }^{10}$

São ainda os dados epigráficos, concretamente a tabula Lougeiorum, datada do ano $1,{ }^{11}$ que demonstram que a criação dos conventos jurídicos foi igualmente obra de Augusto e não dos imperadores flávios, conforme foi tradicionalmente sugerido. De facto, a referência feita naquele documento ao conventus Arae Augustae não parece deixar dúvidas quanto à cronologia da subdivisão das províncias em unidades administrativas de carácter judicial, entregues a legati iuridici,${ }^{12}$ o que demonstra o interesse particular de Augusto pela organização dos territórios hispânicos.

Tal como acontece com a organização provincial também a data oficial da criação das cidades do NO permanece problemática, sendo, contudo, genericamente admitido que ela possa situar-se entre os anos 16/13 a.C. De facto, a chave da política administrativa de Augusto, com a necessária reordenação do território, residiu na fundação ex novo de várias cidades e na promoção de núcleos de povoamento já existentes.

No caso do NO peninsular, sabemos hoje que as cidades de Lucus Augusti e de Asturica Augusta se sucederam a acampamentos militares usados nas guerras cantábricas. ${ }^{13}$ Pelo contrário, nada sugere que o mesmo tenha acontecido com Bracara Augusta, cujos dados arqueológicos apontam claramente para uma origem civil, facto que the confere especificidades em termos de povoamento e de composição social que a distinguem das outras duas cidades augustas do NO hispânico. Com efeito, as fontes epigráficas e arqueológicas disponíveis documentam uma forte componente indígena no processo de povoamento da cidade, bem como na organização do seu corpo cívico, constituído, pelo menos parcialmente, pelas elites indígenas originárias

8 Tranoy $1981,146$.

9 AlföLdy 1969, 207.

10 Dopico Caínzos 2008, 35; 2009

11 Pereira Menault 1984.

12 Dopico Caínzos 1986; 2009, 31-53.

13 Rodríguez Colmenero - Covadonga Carreño 1999; Sevillano Fuertes - Vidal Encinas 2002. 
dos principais oppida da região bracarense, cujos nomes estão bem documentados na epigrafia. ${ }^{14}$

Quer a origem civil da cidade, quer a importância assumida pela população indígena no seu processo de criação e desenvolvimento devem ser entendidas no âmbito das particularidades que conformaram o povoamento pré-romano do território em que a cidade se implantou, no coração da área ocupada pelos Bracari, um dos povos mais importantes da fachada ocidental e meridional do NO peninsular, que controlavam, por isso, a região onde foi fundada Bracara Augusta. ${ }^{15}$

Neste contexto, tanto a organização do povoamento, como o desenvolvimento económico atingido pelas comunidades indígenas da região entre Lima e Ave, ao longo do século I a.C., terão influenciado o ambiente que presidiu às relações que se estabeleceram entre os agentes romanos e as elites indígenas da região bracarense, facilitando o processo de negociação que terá conduzido à escolha do local para fundar a nova cidade e ao seu posterior povoamento. Esse processo implicou certamente a concessão de prerrogativas às elites dos castros da área do Bracari, que viriam a integrar o corpo cívico do novo aglomerado, conforme parece sugerir o dossier epigráfico, que documenta claramente o protagonismo dos indígenas e seus descendentes no exercício dos cargos relacionados com as funções que a cidade desempenhava enquanto capital de convento jurídico, designadamente no âmbito do culto imperial.

A localização da nova cidade no contexto do amplo território situado entre os rios Douro e Minho, quer do ponto de vista económico, quer viário, favoreceu o seu protagonismo como centro administrativo e religioso, bem como o seu desenvolvimento económico, potenciado pela atividade agropecuária, ${ }^{16}$ pelo comércio e produção artesanal, ${ }^{17}$ mas também pela exploração mineira dos territórios mais interiores do conventus. ${ }^{18}$ De resto, a significativa atividade económica da nova urbs está bem documentada pela arqueologia, mas também pela epigrafia, que assinala a presença na cidade de cives romani que negociavam em Bracara Augusta, no tempo de Cláudio. ${ }^{19}$

Assim, Bracara Augusta parece ter herdado a centralidade que o coração da área dos Bracari já possuía no período pré-romano, decorrente do facto de constituir um ponto de confluência de uma vasta rede de caminhos naturais, que se foram consolidando ao longo do I milénio a.C. ${ }^{20}$ Estes viriam a servir de base à estrutura da rede viária principal e secundária que assegurou a integração da região no conjunto da Hispânia romana e a necessária ligação da cidade aos principais centros urbanos peninsulares e ao litoral. ${ }^{21}$

Assim, tudo indica que o sítio de Braga deveria constituir, ainda em época pré-romana, um importante centro viário e económico, no coração de uma das zonas mais desenvolvidas do NO peninsular, com solos férteis e água abundante, que permitiram

14 Tranoy - Le Roux 1989-90, 183-230.

15 Martins ET ALII 2005.

16 Carvalho 2008.

17 Morais 2005.

18 Domergue 1990; Lemos - Meireles 2006, 169-183.

19 Alföldy 1966, 363-372; Morais 2005, 70-71.

20 Martins 1990; Lemos 1999, 81-94; 2002, 95-127.

21 Carvalho 2008. 
o florescimento da atividade agrícola, quer na região do médio vale do Cávado, ${ }^{22}$ quer no vale do Ave, ${ }^{23}$ ao longo do século I a.C.

Não possuindo condições topográficas propícias ao desenvolvimento de um povoado fortificado indígena, pela sua baixa altitude $(199 \mathrm{~m})$, relativamente aos castros da região envolvente $(300 \mathrm{~m})$, todos eles com posições de controlo sobre as duas principais bacias hidrográficas, situadas, respetivamente, a norte (Cávado) e a sul (Ave), o sítio onde se implantou a cidade detinha, todavia, algumas características que o tornavam atrativo para as populações que habitavam os castros circundantes.

Constituindo um verdadeiro alvéolo relativamente ao relevo dominante, o local possuía todas as condições para se tornar num ponto de encontro estratégico para as comunidades indígenas da região, onde poderiam ter sido desenvolvidas atividades económicas, religiosas e cultuais. Estas encontram-se arqueologicamente documentadas, quer por materiais, quer por construções. Referimo-nos à presença de cerâmicas de importação e de moedas tardo-republicanas, na Colina do Alto da Cividade, ${ }^{24}$ e ao pequeno balneário indígena, de cronologia pouco precisa (séculos II / I a.C.), descoberto na parte nordeste da cidade, dedicado à prática de banhos rituais. Também o santuário/fonte rupestre da Fonte do Ídolo, dedicado a Nabia, divindade associada à água, à fertilidade e à natureza parece ter uma origem indígena, apesar de ser conhecido apenas na sua configuração romana, obra devida a Celico Fronto, um imigrante originário de Arcóbriga, que nele mandou gravar inscrições e esculpir figuras, tendo então sido dedicado a Tongonabiago. ${ }^{25}$

O sítio onde se implantou Bracara Augusta, que se conforma como uma pequena colina, que remata um esporão montanhoso, aplanado no sentido $\mathrm{E} / \mathrm{O}$, parece ter constituído um local referencial para as populações indígenas que habitavam os castros da região envolvente, pelo menos ao longo do século I a.C. ${ }^{26}$ Assim, parece possível admitir que na escolha do local para instalar a nova urbs tenham pesado fatores de natureza topográfica, mas sobretudo de natureza social, económica e política, tendo em conta a centralidade do sítio de Braga em termos regionais e a diversidade de atividades que parecem ter sido aí desenvolvidas, em época pré-romana, tendo mesmo sido sugerido por A. Tranoy ${ }^{27}$ que o local funcionaria como ponto de reunião política das elites dos castros do território dos Bracari.

Apesar de ser desconhecida a data exata da fundação de Bracara Augusta parece indiscutível associá-la ao protagonismo de Paulus Fabius Maximus, igualmente documentado em Lucus Augusti. ${ }^{28}$ No entanto, enquanto em Lugo o nome do legado surge referido em três estelas associando-se muito provavelmente aos rituais fundacionais da nova cidade, em Bracara Augusta ele é homenageado num pedestal de

22 Martins 1990; Carvalho 2008.

23 Silva 1986; Dinis 1993.

24 Morais1997-98, 47-136; Zabaleta EstéveZ 2000.

25 Garrido Elena ET aLII 2008.

26 Martins 2009.

27 Tranoy 1981, 194.

28 Rodríguez Colmenero 1995, 29. 
estátua dedicado a Augusto pelos bracaraugustanus, no dia do aniversário do legado imperial, sendo datado entre os anos 3 e 2 a.C. ${ }^{29}$

A menção aos bracaraugustanos, igualmente presente numa outra inscrição, com a mesma cronologia, dedicada a Agrippa Postumus, ${ }^{30}$ parece demonstrar que nos momentos próximos da transição da Era existia já no sítio da nova cidade uma comunidade organizada, com capacidade para se expressar em atos de carácter cívico, designadamente, através da construção de monumentos em honra do imperador, entre os quais se inclui o referido pedestal, bem como outros dois, com a mesma tipologia, dedicados ao Genius Caesaris e ao Genius Augusti. ${ }^{31}$ Assim, parece possível admitir que Bracara Augusta tenha conhecido um processo de povoamento inicial que poderá ter-se iniciado posteriormente a 16/15 a.C., sendo certo que, por volta dos anos 4 e 2 a.C., existiria já um corpo cívico que se referenciava pelo nome da cidade, facto que sugere, também, uma efetiva ocupação do novo aglomerado.

Tendo em conta as particularidades históricas e culturais da área meridional e ocidental da Callaecia parece possível admitir que a fundação de Bracara Augusta corresponda, na prática, ao ultimar de um processo de desenvolvimento sociopolítico e económico que caracterizou a região referida no último século antes da nossa Era, período em que a região estaria já pacificada e sob controlo de Roma, muito embora não tenha sido nunca militarmente ocupada. Este enquadramento terá permitido a reorganização das comunidades indígenas, aparentemente sem qualquer interferência direta de Roma, muito embora esteja arqueologicamente demonstrado que as mesmas mantinham relações comerciais com as regiões já romanizadas do sul da Península. A rota atlântica, certamente mais segura e regular depois da expedição de César a Brigantium, por volta de 60 a.C., terá passado a ser controlada por mercadores romanos, permitindo a difusão na região de produções itálicas e da Hispânia meridional. ${ }^{32}$

Certamente com motivações diferenciadas e consideráveis variantes sociais, económicas, urbanísticas e arquitetónicas, resultantes dos particularismos históricos e culturais regionais, mas também das vantagens que o Estado romano podia auferir dos novos territórios, as cidades augustas do NO hispânico protagonizaram estatutos e percursos muito diversos, que conformaram diferentes processos de povoamento e ritmos de aculturação diferenciados.

O protagonismo assumido pelos indígenas na vida económica e na estrutura social de Bracara Augusta ${ }^{33}$ parece demonstrar que a sua criação se deveu a uma decisão política consensual entre Roma e as elites indígenas bracarenses, a qual terá sido precisada com os necessários instrumentos jurídicos e administrativos romanos, que se projetaram no território através de rituais e cerimónias específicas, próprias da tradição fundacional romana de criação de novas civitates. Somente após esses procedimentos se terão realizado os necessários trabalhos de agrimensura de limitatio e centuriatio do território, que precediam as atividades construtivas.

29 Le Roux 1975, 155; Tranoy, 1981, 328.

30 Le Roux 1975, 155-159; 1994, 231 nota 10.

31 Vasconcelos 191, 326; CIL II, 5123.

32 Morais 2005.

33 Martins 2009, 188-190. 


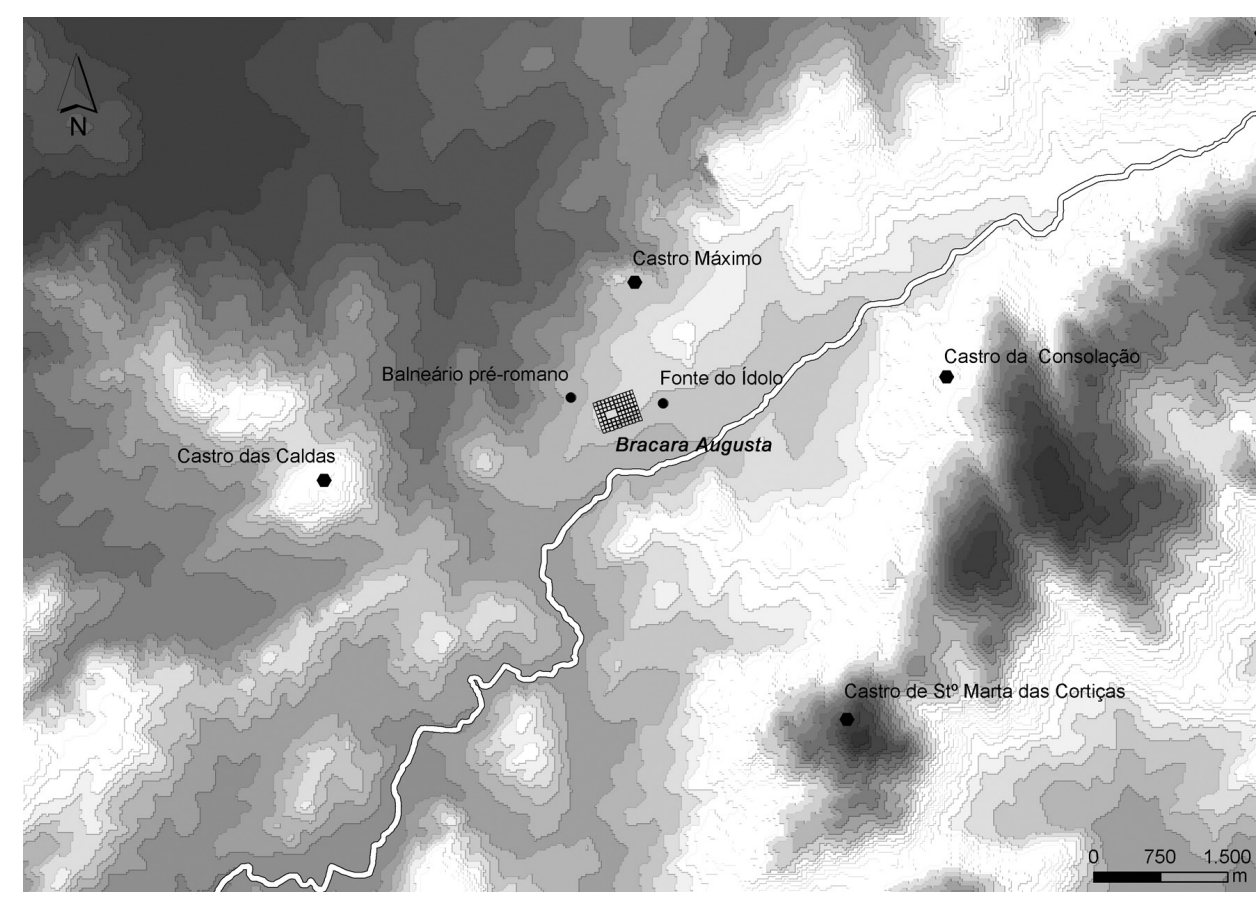

Fig. 2. Implantação de Bracara Augusta na região envolvente.

\section{Urbanismo}

A valorização dos dados arqueológicos obtidos nas escavações realizadas na área urbana de Braga, desde 1976, no âmbito do "Projeto de Bracara Augusta", permite hoje esboçar uma imagem coerente da organização do espaço urbano, que sabemos ter sido objeto de planificação, atendendo à orientação geral da grande maioria das construções e à identificação de eixos viários, pórticos e de cloacas.

A paulatina acumulação de vestígios resultantes de várias intervenções arqueológicas permitiu a elaboração de sucessivas propostas para o traçado da cidade romana, ${ }^{34}$ que, muito embora pouco tenham variado em termos das dimensões das insulae, registam diferentes hipóteses relativamente à localização dos eixos viários principais da cidade, bem como à extensão da própria área planificada. Essas variantes decorrem dos constrangimentos próprios da arqueologia urbana, entre os quais podemos destacar as significativas descontinuidades nas áreas intervencionadas, a imprecisão dos limites da área que foi planificada e o facto da maioria das evidências disponíveis se reportarem a construções da época flávia e do período antonino. São exatamente os vestígios desses períodos, dispersos por toda a cidade, que nos remetem para uma

34 Martins - Delgado 1989-90; Ribeiro 2008; Martins 2009. 
prévia planificação do espaço urbano, com a marcação de eixos viários principais e secundários e a delimitação de lotes construtivos.

Sabemos que o programa de fundação de uma nova cidade era essencialmente um exercício prático de divisão e distribuição do espaço urbano, durante o qual se definiam os locais reservados aos edifícios públicos, os que deveriam corresponder a ruas e aqueles que seriam espaços privados. Assim, basicamente a distribuição do espaço urbano definia o espaço público e privado e dentro deste a hierarquia social representada pela desigual dimensão dos lotes atribuídos. Por outro lado, a trama viária relacionava-se com o forum e com as vias que ligavam a cidade ao território e a outras cidades. Assim, aconteceu com Bracara Augusta, verificando-se que o cadastro do território segue basicamente a orientação dos eixos da cidade. ${ }^{35}$

Os eixos viários de Bracara Augusta registam uma orientação dominante NNO/ $\mathrm{SSE}$ e ENE/SSO, com um desvio de cerca de $16^{\circ}$ em relação ao Norte. O cardo máximo representa o eixo viário melhor conhecido, sobretudo no seu tramo norte, apresentando uma largura de 7,24 m (24 pés). Presumimos que este eixo acompanharia o limite nascente do forum, desenvolvendo-se para sul com a mesma orientação. Do decumano máximo pouco se sabe, sendo suposto que o seu segmento poente se encontra fossilizado na atual rua de S. Sebastião e que o seu traçado nascente se prolongaria no eixo da Via XVII, arqueologicamente documentada. ${ }^{36}$

Várias intervenções arqueológicas permitiram exumar vestígios associados à trama viária secundária, constituídos por restos de pavimentos, ou de estruturas delimitadoras, como sejam os pórticos, ou mesmo alguns muros. Tendo por base os elementos referidos é possível estimar para esses eixos uma largura média de 12 pés, o que sugere que o traçado da trama viária de Bracara Augusta obedecia a um rudimentar princípio de hierarquização. No entanto, estão documentadas algumas ruas que possuem larguras ligeiramente diferentes, variação que julgamos dever-se à própria dinâmica construtiva da cidade, decorrente do processo de ocupação dos quarteirões e da edificação dos pórticos. De facto, importa sublinhar que o modelo concetual da cidade, que seria definido e implementado no terreno pelos agrimensores, sofria sempre alterações, resultantes quer das condicionantes topográficas do terreno, quer das atividades construtivas.

Anexos às ruas encontram-se os pórticos, que funcionavam como verdadeiros espaços de articulação do sistema viário com as áreas construídas dos quarteirões, ${ }^{37}$ servindo para a circulação e proteção dos transeuntes, mas também de extensão das atividades que tinham lugar nas tabernae, que se dispunham na parte baixa das casas. Com ampla difusão nas cidades do ocidente do Império, os pórticos constituem um elemento característico da estrutura urbana alto-imperial de Bracara Augusta, tendo sido documentados em todas as zonas arqueológicas que correspondem a áreas habitacionais, ${ }^{38}$ estando igualmente asociados às fachadas de alguns edificios públicos. A

35 Carvalho 2008; 2012, 129-146.

36 MARTINS ET ALII 2010; FonTES ET ALII 2010a; $2010 \mathrm{~b}$.

37 Alberti 2006, 110.

38 Martins ET ALII 2012; MagalHães 2011. 
grande maioria dos pórticos detetados até ao momento revela uma largura média de 12 pés, muito embora existam casos em que se aproximam dos 10 pés.

Tomando por referência a distância entre os eixos das ruas conhecidas encontramos uma medida recorrente de 156 pés $(46,20 \mathrm{~m})$, quer no sentido $\mathrm{N} / \mathrm{S}$, quer no sentido $\mathrm{E} / \mathrm{O}$, facto que sugere que estamos perante um modelo planimétrico muito regular, que recolhe paralelo nas subdivisões agrárias que formalizavam a centuriação tradicional. ${ }^{39}$ Por sua vez, se considerarmos os 12 pés como a medida padrão para os eixos viários secundários e para as ruas, apuramos o valor de 120 pés quadrados para os lotes de construção privados, medida correspondente a 1 actus $(35,52 \mathrm{~m}$ x 35,52 $\mathrm{m})$ que apenas variava nos quarteirões limítrofes, quer do cardo, quer do decumano máximos, onde as áreas reservadas à construção seriam ligeiramente menores.

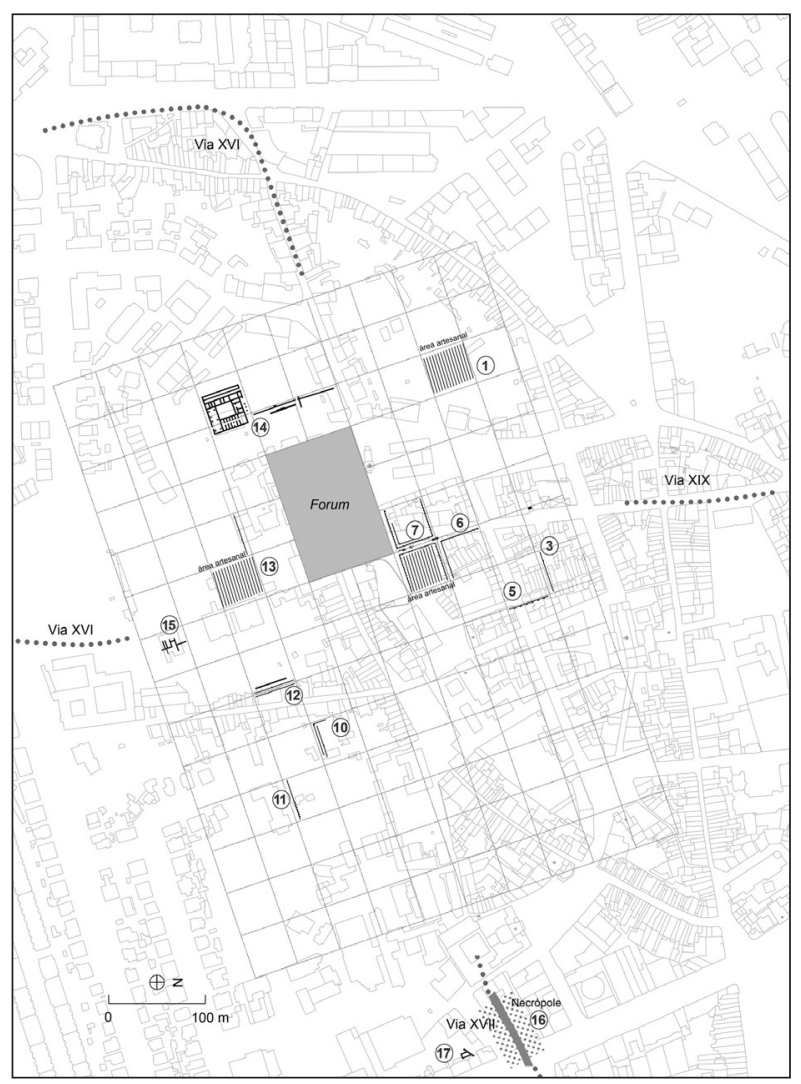

Fig. 3. Proposta de malha urbana com vestígios da época de Augusto: 1. Carvalheiras; 3. R. Gualdim Pais; 5. - Rua Afonso Henriques; 6 - Frei Caetano Brandão/Santo António das Travessas; 7 - ex Albergue Distrital; 10 - S. Geraldo 27-31; 11 - Misericórdia; 12 - S. Geraldo 34; 13 - Antigas Cavalariças; 14 - Edifício pré termal; 15 - domus do mosaico; 16 e 17 necrópole da Via XVII.

39 Castagnoli $1971,120$. 
Um dos principais problemas que se coloca à análise da planimetria fundacional de Bracara Augusta está relacionado com o forum, sobre o qual nada se conhece, muito embora a sua localização seja sugerida pela interpretação global da forma urbis, pelo aparecimento de elementos arquitetónicos de grandes dimensões ${ }^{40}$ e por uma referência contida num mapa do século XVI, que o situa nas imediações da capela de S. Sebastião. Tendo em conta o local onde se situa este monumento e a praça que se estende a sul do mesmo, somos tentados a admitir que o forum se situava na extensa plataforma que corresponde ao atual Largo Paulo Orósio, que constituía a área mais elevada da cidade, antes de ter sido rebaixada nos inícios do século XX. O forum surge assim descentrado relativamente à planta da cidade, situação que poderá explicar-se por razões topográficas. Por outro lado, e também por critérios meramente topográficos, julgamos poder admitir que deveria desenhar um retângulo, com o eixo maior disposto no sentido N/NE-S/SO, podendo ter-lhe sido reservada a área correspondente a 3 quarteirões, no sentido do comprimento, por dois de largura. Se deduzirmos o valor das áreas reservadas aos eixos viários que rodeariam o recinto obtemos para o mesmo um comprimento máximo de cerca de 450 pés $(133,45 \mathrm{~m})$ e uma largura de 294 pés $(87,17 \mathrm{~m})$.

O facto de Bracara Augusta não possuir uma muralha fundacional dificulta sobremaneira o exercício de delimitação do pomoerium sempre mais fácil de definir quando o mesmo era materializado por portas e construções defensivas. Tão pouco nos serve o traçado da muralha dos finais do século III / inícios do século IV, uma vez que esta encerrou uma extensa área que integrou construções com orientações divergentes dos eixos da malha urbana, que supomos já articuladas com a periferia imediata da cidade. Nem mesmo a localização das necrópoles ajuda a delimitar a primitiva área urbana, pois os vestígios conhecidos situam-se todos a uma distância considerável dos hipotéticos limites da cidade. ${ }^{41}$ Neste sentido, a definição da área que terá sido inicialmente planificada tem que ser avaliada em função de critérios topográficos, associados à interpretação dos vestígios construtivos exumados até ao momento que oferecem a orientação dominante dos eixos viários da cidade. Tendo por base esses critérios é possível sugerir que o traçado fundacional tenha projetado uma cidade de planta perfeitamente retangular, seguindo os padrões de algumas cidades italianas de fundação augústea. A área hipoteticamente projetada teria como eixo maior, no sentido N/NO-S/SE, cerca de 10 módulos de 156 pés $(1560$ pés $=461.76$ $\mathrm{m})$, o que equivaleria a cerca de 2,5 estádios romanos e, no sentido E/NE-O/SO, cerca de 14 módulos ( 2184 pés $=650,30 \mathrm{~m}$ ), correspondente a 3,5 estádios. Tendo em conta as medidas consideradas poderíamos estimar que a superfície total planificada cobria uma área com cerca de $298.511 \mathrm{~m}^{2}$, ou seja, 29,85 ha.

O processo de ocupação do novo espaço urbano deverá ter-se iniciado logo após as operações cadastrais, que talvez se tenham seguido de imediato à decisão de fundação da cidade, em torno de 16/15 a.C., considerando os dados arqueológicos e epigráficos disponíveis. Na verdade, os vestígios exumados em numerosas escavações documentam atividades em vários pontos da área urbana e enterramentos claramente

40 Ribeiro 2010, 326-328.

41 Martins - Delgado 1989-90. 
anteriores à transição da Era, o que permite supor uma fixação de populações no local durante a última década a.C. No mesmo período terão sido iniciados os trabalhos de construção da rede viária principal, com destaque para as vias XVI, XVII e XIX, de cronologia augústea, sendo certo que a população urbana adquiriu rapidamente uma consciência cívica de pertença ao novo aglomerado, bem expressa na menção aos bracaraugustanos, referidos em pedestais de estátuas, dedicados a Augusto e respetiva família, entre os anos 3-2 a.C. e 4 d.C. Por outro lado, a existência destes monumentos honoríficos exigiria a existência de um forum, cuja construção deve ter sido iniciada na última década antes da transição da Era.

Os quarteirões envolventes do forum registam durante as primeiras décadas do século I uma intensa atividade artesanal, eventualmente desenvolvida em construções de carácter fruste, enquanto se consolidavam as importações, o que indica que a cidade se desenvolveu, logo desde as suas origens, como importante polo comercial, como bem testemunha a homenagem, feita no tempo de Cláudio, pelos cidadãos romanos que negociavam na cidade a C. Caetronius Miccio. ${ }^{42}$

De meados do século I data a construção da cloaca do cardo máximo, para onde passam a confluir as águas sujas e pluviais. A estruturação deste sistema hidráulico de saneamento urbano parece articular-se com o início de uma ocupação sistemática dos quarteirões por domus, na sua grande maioria datáveis posteriormente aos meados do século I d.C. ${ }^{43}$ Este facto documenta a consolidação do tecido urbano, mas, também, a interiorização por parte da população residente, maioritariamente de origem indígena, de uma educação de uso e compreensão do significado simbólico e ideológico dos espaços e de formas arquitetónicas de matriz helenística, de que eram expressão as domus de peristilo. ${ }^{44}$

O desenvolvimento das atividades económicas e construtivas que dinamizaram a cidade, ao longo de todo o século I, bem como as que se associaram à exploração dos recursos de várias áreas do conventus bracarensis, terá justificado a criação de uma elite urbana com capacidade para sustentar um programa de construção de grandes edifícios públicos, entre os quais se encontram várias termas públicas, ${ }^{45}$ um teatro ${ }^{46} \mathrm{e}$ um anfiteatro. ${ }^{47} \mathrm{~A}$ grande maioria desses edifícios data dos inícios do século II, facto que parece demonstrar que os programas edilícios articulados com a monumentalização do espaço urbano foram implementados após um século de desenvolvimento da cidade e de consolidação da sua comunidade cívica.

42 Alföldy 1966, 363-372; Morais 2005, 70-71.

43 Magalhães 2010.

44 Martins et aliI 2012; Magalhães 2010.

45 Martins 2005; MarTins ET ALII 2011, 69-102.

46 Martins ET ALII 2013.

47 Morais 2001, 55-76. 


\section{Povoamento e organização do território}

Paralelamente à fundação de três centros urbanos no NO peninsular, inicia-se a implantação de uma rede viária que joga um papel essencial na estruturação do povoamento, com destaque para as vias XVI (Bracara-Olisipo), XVII (Bracara-Asturica) e XIX (Bracara-Lucus) cuja abertura ocorre ainda no tempo de Augusto. Esta rede de itinerários principais reforça a articulação dos novos centros urbanos e favorece, seguramente, a disseminação de novos modelos de ocupação do espaço. Cidades e rede viária constituem, pois, infra-estruturas para a compreensão dos processos de organização do território a várias escalas.

À escala da região ocidental do território do conventus bracarensis, a presença romana está na origem de uma remodelação paulatina, lenta mas profunda, do sistema de povoamento anterior. ${ }^{48} \mathrm{O}$ processo traduz-se, antes de mais, no aparecimento e desenvolvimento de uma rede de aglomerados secundários, ou vici, fortemente articulados com a rede viária e/ou orientados para a exploração de recursos específicos, nomeadamente termais. A exploração dos recursos agrícolas, por seu turno, pode ser perspetivada a partir da repartição e cronologia das villae e de outros estabelecimentos rurais. Pese embora o caráter muito lacunar da informação arqueológica, é possível identificar 43 villae, das quais somente oito foram objeto de escavações. Num primeiro momento, as villae e os povoados fortificados parecem ter coabitado num processo de interação e de mobilidade da população indígena que se poderá situar durante a primeira metade do século I. De facto, os dados recolhidos nas villae escavadas revelaram materiais alto imperiais, o que assinala uma implantação precoce da exploração agrícola segundo moldes romanos. Esta nova forma de ocupação do espaço, implicando, antes de mais, a privatização da terra, deverá ser entendida como parte de um processo que terá ocorrido em ritmos variados. ${ }^{49}$

Numa outra escala, importa avaliar o território próximo de Bracara Augusta no âmbito das transformações operadas pela sua fundação. Neste contexto, é visível um processo de povoamento sistemático, em particular na região de veiga entre a cidade e o rio Cávado, a norte, e a área conhecida como veiga do Penso, a sul. A distribuição espacial do povoamento demonstra uma intensa ocupação em anéis concêntricos em torno da cidade romana, atingindo um aro de 5 a $8 \mathrm{~km}$.

Uma observação mais atenta permite-nos identificar 13 estabelecimentos, que poderão eventualmente corresponder a villae, no território em torno da cidade, o que demonstra a estreita relação entre cidade e campo, reforçada, naturalmente, pela rede viária. Neste conjunto, importa salientar a villa de Dume, parcialmente escavada, que corresponde provavelmente a uma instalação coeva dos primeiros momentos de existência da cidade de Braga. ${ }^{50}$

No território em análise, foi ainda identificada uma razoável densidade de outros vestígios de época romana, difíceis de aferir em termos de tipologia. Para além de equipamentos integrados nas villae, haveria, concerteza, unidades de exploração

48 Carvalho 2008; Trément - Carvalho 2013; Martins - Carvalho 2010.

49 Carvalho 2008, 45-50, 235-236; Carvalho - Cruz no prelo.

50 Fontes1991-1992; FonTES ET ALII 2009. 
agrária de tipo familiar, de menores dimensões, habitualmente classificadas como casais ou quintas, que explorariam os recursos agrícolas em propriedades de pequena ou média dimensão.

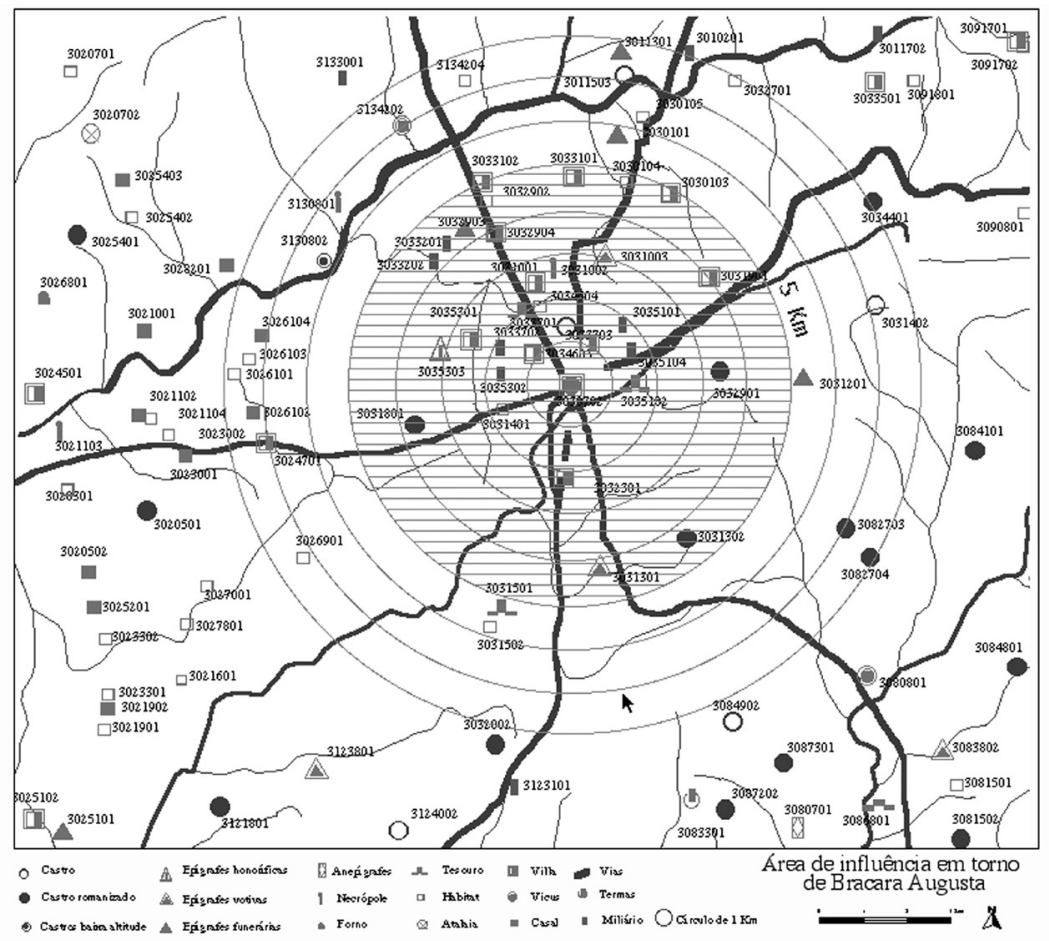

Fig. 4. Povoamento em torno da cidade de Bracara Augusta.

A recuperação de um cadastro romano em torno de Bracara Augusta assume uma importância fulcral na análise do processo de integração deste território sob o domínio romano. Sintetizaremos, aqui, os resultados mais significativos desta pesquisa. ${ }^{51}$

Os alinhamentos mais significativos detetados na área em estudo indicam uma organização de um cadastro romano, com uma malha $20 \times 20$ actus e uma orientação de $16^{\circ} \mathrm{NNO}$. Esta malha e orientação foram confirmadas pelo achado de elementos delimitadores que se revestem do maior interesse.

Trata-se, antes de mais, de dois cipos gromáticos talhados em blocos de cerca de 0,50 m de altura visível, por cerca de 0,40 m de largura, sendo possível ver num deles vestígios de almofadado em duas das faces. Ambos apresentam a face superior perfeitamente alisada, onde se gravou uma cruz (decussis) que a ocupa completamente. Ambas as peças encontram-se no mesmo alinhamento e mantêm uma distância entre si de, precisamente, uma centúria (20 actus).

51 Carvalho2008; Carvalho 2012; Carvalho - Mendes 2009-2010. 


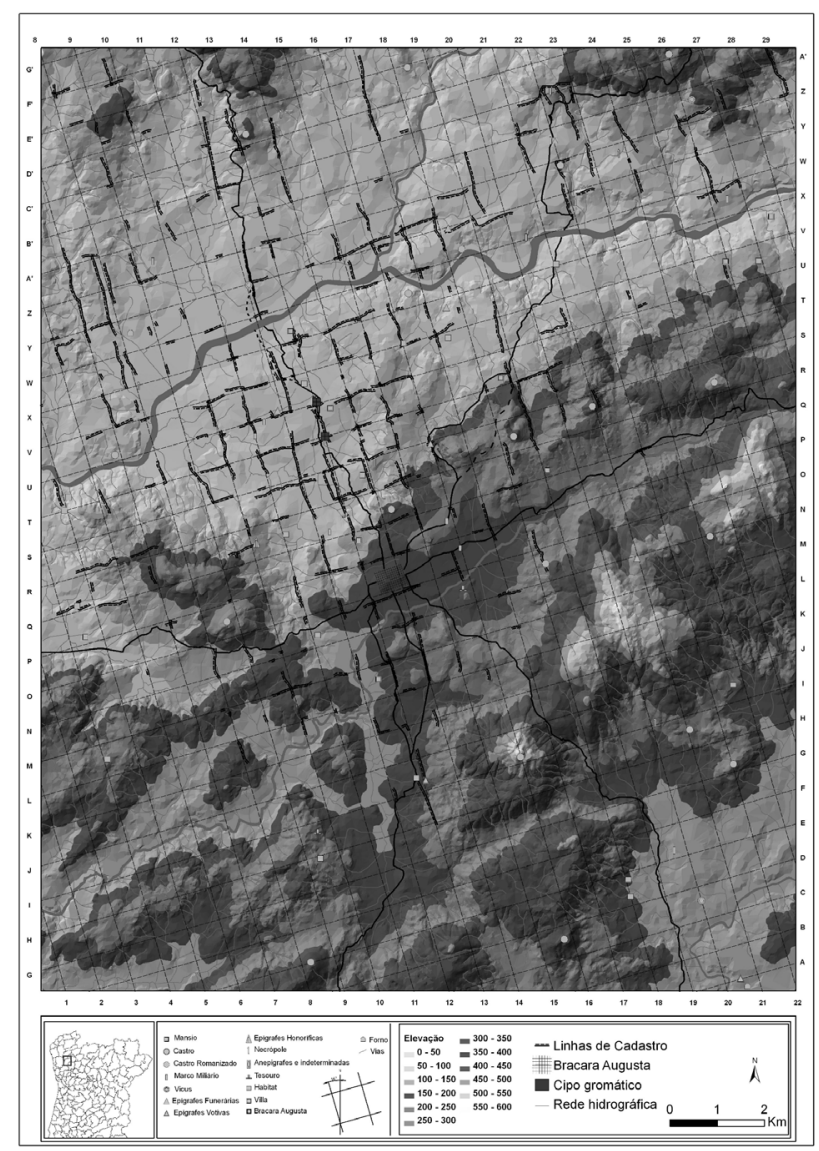

Fig. 5. Cadastro romano em torno da cidade de Bracara Augusta.

O primeiro monumento encontrado em prospeção (cipo 1) situa-se no lugar de Felgueira e serve de limite entre as freguesias de Dume e S. Pedro de Merelim. Trata-se de um monumento de granito, com duas faces almofadadas, topo perfeitamente liso e duas linhas que se cruzam no topo (decussis). A sondagem arqueológica efetuada no monumento, embora não nos tenha dado informação arqueológica substancial, permitiu-nos comprovar a dimensão do monumento : $1 \mathrm{~m}$ de altura por $40 / 45 \mathrm{~cm}$ de largura.

O segundo monumento (cipo 2) limita as freguesias de S. Pedro de Merelim, Dume e Palmeira. Trata-se de um monumento de granito, idêntico ao anterior mas em pior estado de conservação, com $0,47 \mathrm{~m}$ de altura máxima visível e $0,28 \mathrm{~m}$ de largura. $\mathrm{O}$ facto de ambos os monumentos possuírem a função de marcos delimitadores de freguesias implica que a sua implantação é rigorosamente mantida quer pelas populações quer pelos responsáveis públicos. É precisamente a sua função delimitadora, 
constantemente renovada, ao longo do tempo que garantiu a sua permanência até aos dias de hoje.

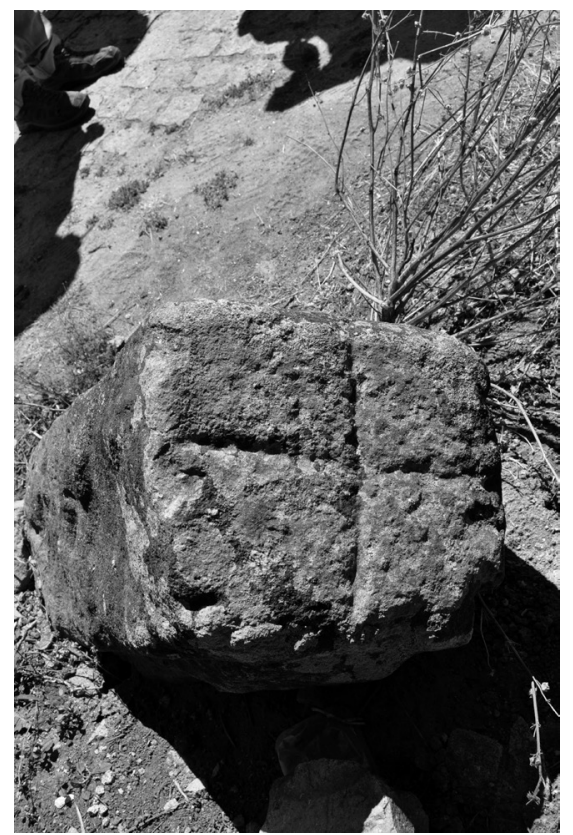

Fig. 6. Cipo Gromático encontrado em Felgueira, limite das freguesias de Dume e S. Pedro de Merelim, concelho de Braga.

A leste destes cipos, localiza-se um monumento que se assemelha a algumas das representações de limites que ocorrem nos tratados de agrimensura romanos e medievais. ${ }^{52}$ Com efeito, no lugar conhecido como Fonte de S. Vicente, no sopé da vertente oeste de Montariol, existe uma nascente de água que brota da rocha onde foi talhado um tanque quadrado que aparenta ser uma archa petrinea, elemento usualmente referido na documentação medieval como marcador de limites. Junto ao local encontra-se tijolo e tegulae. ${ }^{53}$ De um dos muros junto à fonte foi retirada uma ara votiva dedicada a Marte Tarbucelis por uma família de pisoeiros. ${ }^{54}$ A presença desta archa petrinea, curiosamente associada a uma inscrição votiva a Marte, deverá assinalar o remate leste de uma centúria romana situada a norte da cidade, no sopé de uma zona mais elevada (Montariol) que terá ficado fora desta adsignatio.

A zona centuriada configura, assim, um amplo retângulo, num território de veigas, cortado pelas vias romanas que saíam de Braga. Esta malha de centúrias de 20 x 20 actus, com uma orientação de $16^{\circ} \mathrm{NNO}$, encontra-se perfeitamente adaptada às orientações estruturantes do relevo e da rede hidrográfica. O carácter sistemático desta

52 Chouquer - FaVory 1992; Portet 2004; AriÑo Gil et alit 2004.

53 FONTES 1993.

54 SAntos ET ALII 1983, 183-205. 
orientação, a modulação em actus e a sua articulação quer com o traçado da cidade quer com os principais eixos viários da região rasgados na época de Augusto permitem sugerir uma centuriação ligada à fundação de Bracara Augusta e à projeção da rede viária na época júlio-claudiana.

\section{Considerações finais}

A criação das cidades do NO peninsular, entre as quais se encontra Bracara Augusta, insere-se no complexo cenário de reordenamento de territórios e populações que afetou a Hispânia posteriormente ao fim das guerras cantábricas, que implicava a existência de centros urbanos capazes de se constituírem como sedes administrativas das comunidades e populi recém-integrados no Império. Neste contexto, a fundação de Bracara Augusta emerge de uma clara convergência de interesses por parte de Roma e das comunidades indígenas, representando, simultaneamente, uma clara continuidade do desenvolvimento das comunidades da área dos Bracari, com os seus oppida. Enquanto Roma forneceu o que podemos designar por "sistema tecnológico de cidade", que incluía os instrumentos de ordenação do espaço físico, as técnicas construtivas, as tipologias arquitetónicas de prestígio, ou a cultura urbana de matriz helenística, as comunidades indígenas forneceram as suas elites e a mão-de-obra indispensável à concretização do novo projeto urbano. Sem dúvida que as elites indígenas terão tido claros benefícios com o novo contexto político e administrativo que se sucedeu ao fim das guerras cantábricas, acordando a sua fixação numa nova estrutura cívica, obtendo por essa via um instrumento legal de controlo privado dos recursos do território, que lhes concedia indiscutíveis dividendos económicos e sociais, certamente utilizados para aumentar o seu status na nova ordem social.

Bracara Augusta irá beneficiar da sua particular localização privilegiada no âmbito do NO peninsular, sendo a cidade mais meridional das três capitais conventuais fundadas por Augusto. Inserida no centro de uma região que conheceu um precoce contacto com as tropas romanas (138-136 a.C.) e que regista um particular processo de desenvolvimento, ao longo do século I a.C., que incluiu a concentração de populações em oppida, a assinalar uma clara hierarquia na estrutura do povoamento pré-romano, a cidade viria a conhecer uma forte componente indígena na matriz do seu corpo cívico, que parece registar uma fácil assimilação, quer dos novos modelos de organização, quer dos padrões culturais característicos do mundo romano.

O protagonismo assumido pelos indígenas na vida económica e na estrutura social de Bracara Augusta parece demonstrar que a sua criação se deveu a uma decisão política consensual entre Roma e as elites indígenas bracarenses. De acordo com os dados disponíveis poderemos considerar que, nos anos que se seguiram aos rituais fundacionais, o espaço escolhido para implantar a cidade foi dotado de uma malha ortogonal de eixos viários, tendo por base um modelo prévio, que permitiu definir as áreas públicas e aquelas que seriam destinadas aos privados. A planificação da cidade fixou os limites de uma área urbana retangular, com o cardo e decumano máximos descentrados, cujo cruzamento formalizou o canto nordeste do forum. 
Julgamos ser possível admitir que o cadastro romano, identificado em torno de Bracara Augusta, deverá ser coevo da fundação da cidade, registando alinhamentos semelhantes aos da área urbana e uma malha de centúrias de 20x20 actus. A sua implantação, bem como os novos estabelecimentos de tipo villa que surgem no território em torno da cidade contribuíram decididamente para desenhar uma nova paisagem rural, enquanto a densa rede de vias que o cruzavam favoreceu o desenvolvimento de novos aglomerados (vici), explicando igualmente a sobrevivência de alguns povoados fortificados de origem indígena.

\section{BibLIOGRAFÍA}

AlBerTi, G. (2006): "La communication entre la rue et la maison: quelques exemples de Gaule Belgique et des Germanies”, [en] P. Ballet - N. Dieudonne-Glad - C. Saliou, (eds.), La rue dans l'Antiquité. Définition, Aménagement, Devenir, Rennes, 109-115.

AlFÖLDY, G.

(1966): "Um “cursus” senatorial de Bracara Augusta”, Revista de Guimarães 76/2, 363372.

(1969): Fasti Hispanienses. Senatorische Reichsbeamte und Offiziere in den spanischen provinzen des römischen Reiches von Augustus bis Diokletian, Wiesbaden.

Ariño Gil, E. - Gurt Esparraguerra, J. M. - Palet Martínez, J. M. (2004): El pasado presente. Arqueología de los paisajes en la Hispania romana, (=Acta salmanticensia. Estudios históricos \& geográficos 122), Barcelona.

Braga, C. (2011): Rituais funerários em Bracara Augusta: o novo núcleo de necrópole da Via XVII, UMinho, Braga.

Bravo Castañeda, G. (2007): Hispania. La epopeya de los romanos en la Península, Madrid.

Castagnoli, F. (1971): Ortogonal town in antiquity, Cambridge.

CARvalho, H. - Cruz, M. (no prelo): "Peuplement et organisation du paysage dans la partie occidentale du Conventus Bracarensis", [en] IV Convegno Internazionale di Studi Veleiati (20-21 Settembre 2013), Veleia.

Carvalho, $\mathrm{H}$.

(2008): O povoamento romano na fachada ocidental do Conventus Bracarensis, Braga. (2012): "Marcadores da paisagem e intervenção cadastral no território próximo de Bracara Augusta (Hispania Citerior Tarraconensis)", Archivo Español de Arqueologia 85, 129146.

Carvalho, H. - Mendes, F. A. (2009-2010): “Centuriazione e evoluzione degli assetti agrari intorno alla città di Bracara Augusta (Hispania Citerior Tarraconensis)", Agri Centuriati 6, 193-204.

Chouquer, G. - Favory, F. (1992): Les arpenteurs romains. Théorie et pratique, Paris.

Dinis, A. P. (1993): Ordenamento do território da bacia do Ave no I milénio a.C., Porto.

Dopico Caínzos, M. D.

(1988): La Tabula Lougeiorum. Estudios sobre la implantación romana en Hispania, Vitoria. 
(2009): “A transformação dos pobos do noroeste hispánico na época de Augusto: a evidencia epigráfica", [en] D. Dopico Caínzos - M. Villanueva Acuña - Rodríguez Alvarez (eds.), Do castro á Cidade. A romanización na Gallaecia e na Hispânia indoeuropea, Lugo, 3153.

FONTES, L. F. O.

(1991-1992): "Salvamento Arqueológico de Dume (Braga). Resultados das Campanhas de 1989-90 e 1991-92", Cadernos de Arqueologia 8-9, 199-230.

(1993): "Inventário de Sítios Arqueológicos de Concelho de Braga", Mínia 3, série 1, 3188.

Fontes, L. - Martins, M. - Ribeiro, M. C. - Carvalho, H. (2010): “A cidade de Braga e o seu território nos séculos V-VII", [en] A. Garcia - R. Izquierdo - L. Olmo - D. Peris (eds.), Espacios Urbanos en el Occidente Mediterráneo (s. VI-VIII), Toledo, 255-262.

Fontes, L.- Martins, M. - Andrade, F. (2010a): Salvamento de Bracara Augusta: quarteirão dos CTT - interligação Túnel Avenida da Liberdade (BRA 09 CTT-ITAVL). Relatório final, Braga.

Fontes, L., - Martins, M., - Sendas, J. - Catalão, S. (2010b): Salvamento de Bracara Augusta: ampliação do túnel da Avenida da Liberdade (BRA 08-09 TAVL). Relatório final, Braga.

Garrido Elena, G. A. - MAr, R. - Martins, M. (2008): A Fonte do Ídolo: análise, interpretação e reconstituição do santuário, (Bracara Augusta. Escavações Arqueológicas 4), Braga.

Grau, L. A. - Hoyas, J. L. (eds.) 2001: El bronce de Bembibre: un edicto del emperador Augusto del año 15 a.C., León.

Lemos, F. S.

(1999): "O contexto geográfico da fundação de Bracara Augusta”, Forum 25, 81-94.

(2002): "Bracara Augusta - A Grande Plataforma viária do Noroeste Peninsular", Forum 31, 95-127.

Lemos, F. S. - Meireles, C. (2006): "Mineração aurífera no Conventus de Bracara Augusta", [en] $3^{\circ}$ Simpósio sobre mineração e metalurgia históricas no Sudoeste europeu, Porto, 169-183.

Le Roux, P.

(1975): “Aux Origines de Braga (Bracara Augusta)", Bracara Augusta, 155-157.

(1994): “Bracara Augusta, ville latine”, Trabalhos de Antropologia e Etnologia 34/1-2, 229-241.

Magalhães, F. (2010): Arquitectura doméstica em Bracara Augusta, Braga.

MARTINS, M.

(1990): O povoamento proto-histórico e a romanização da bacia do curso médio do Cávado, (Cadernos de Arqueologia. Monografias 5), Braga.

(2005): As termas romanas do Alto da Cividade. Um exemplo de arquitectura pública em Bracara Augusta, (Escavações Arqueológicas 1), Braga.

(2009): "Bracara Augusta. Panorama e estado da questão sobre o seu urbanismo", [en] D. Dopico Caínzos - M. Villanueva Acuña - Rodríguez Alvarez (eds.), Do Castro á Cidade. A romanización na Gallaecia e na Hispânia indoeuropea, Lugo, 181-211.

Martins, M. - Delgado, M. (1989-90): “As necrópoles de Bracara Augusta. A. Os dados arqueológicos”, Cadernos de Arqueologia 6/7, 41-186. 
Martins, M. - CARvalho, H. (2010): "Bracara Augusta and the changing of rural landscape", [en] C. Corsi - F. Vermeulen (eds.), Changing Landscapes. The impact of roman towns in the Western Mediterranean. Proceedings of the International Colloquium, Bologna, 281298.

Martins, M. - Fontes, L. - Braga, C. -Braga, J. - Magalhães, F. - Sendas, J. (2010): Salvamento de Bracara Augusta : quarteirão dos CTT - Avenida da Liberdade (BRA 08-09 CTT). Relatório final, Braga.

Martins, M. - Lemos, F. S. - Pérez Losada, F. (2005): “O povoamento romano no território dos galaicos bracarenses”, [en], C. Fernández Ochoa - P. García Díaz (eds,), Unidad y diversidad en el arco Atlántico en época romana, BAR International Series 137, Oxford, 279-296.

Martins, M. - Ribeiro, M. C. - Baptista, J. M. (2011): “As termas públicas de Bracara Augusta e o abastecimento de água da cidade romana”, [en] Actas del Seminario Internacional Aquae Sacrae. Agua y sacralidad en época antigua, Girona, 69-102.

Martins, M. - Ribeiro, R. - Magalhães, F. (2006): “A arqueologia em Braga e a descoberta do teatro romano de Bracara Augusta”, Forum 40, 9-30.

Martins, M. - Ribeiro, R. - Magalhães, F. - Braga, C. (2012): "Urbanismo e arquitetura de Bracara Augusta. Sociedade, economia e lazer", [en] M. C. Ribeiro - A. Melo (coords.), Evolução da Paisagem Urbana: Economia e Sociedade, Braga, 29-67.

Martins, M. - Mar, R. - Ribeiro, R. - Magalhães, F. (2013): "A construção do teatro romano de Bracara Augusta,", [en] A. Melo - M. C. Ribeiro (coords.), História da Construção. Arquiteturas e técnicas Construtivas, Braga, 41-76.

Morais, R. M. L.

(1997-98): “Importações de cerâmicas finas em Bracara Augusta: da fundação até à época flávia”, Cadernos de Arqueologia 14/15, 47-136.

(2001): "Breve ensaio sobre o anfiteatro de Bracara Augusta", Forum 30, 55-76. (2005): Autarcia e Comércio em Bracara Augusta. Contributo para o estudo económico da cidade no período Alto-Imperial, Bracara Augusta, Escavações Arqueológicas 2, Braga.

Portet, P. (2004): Bertrand Boysset, la vie et les auvres techniques d'un arpenteur médiéval (v. $1355-v .1416)$, Paris.

RiBEIRO, J. (2010): Arquitectura romana em Bracara Augusta: uma análise das técnicas edilícias, Braga.

RiBeIRo, M. C. (2008): Braga entre a época romana e a Idade Moderna. Uma metodologia de análise para a leitura da evolução da paisagem urbana, UMinho, Braga.

Rodríguez Colmenero, A. (1995): Lucus Augusti. Urbs Romana. Los orígenes de la ciudad de Lugo, Lugo.

Rodríguez Colmenero, A. - Covadonga Carreño, M. (1999): "Lucus Augusti, Capital romana del finisterre hispânico", [en] Actas da Mesa Redonda, Emergência e Desenvolvimento das cidades romanas no norte da Península Ibérica, Lugo, 115-132.

Santos, L. A. - Le Roux, P. - Tranoy, A. (1983): "Inscrições romanas do Museu Pio XII em Braga", Bracara Augusta 37 83-84 (96-97), 183-205.

SeVillano Fuertes, A. - Vidal Encinas, J. M. (2002): Urbs Magnifica. Una aproximación a la Arqueología de Asturica Augusta Astorga, León, Astorga.

Silva, A. C. F. (1986): A cultura castreja no Noroeste de Portugal, Paços de Ferreira. 
Trément, F. - Carvalho, H. (2013): "Romanisation et développement: approche comparée des territoires des Bracari (Tarraconaise) et des Arverni (Aquitaine). Une perspective de longue durée (IIe s. av.J.C.-IIe s. ap. J.C.)", [en] L'Ager Tarraconensis. Paisatge, poblament, cultura material i historia, Tarragona, 249-269.

Tranoy, A. (1981): La Galice romaine. Recherches sur le Nord-Ouest de la Péninsule Ibérique dans l'Antiquité, Paris.

Tranoy, A. - Le Roux, P. (1989-90): “As necrópoles romanas de Bracara Augusta - Les inscriptions funéraires”, Cadernos de Arqueologia 6-7, Braga, 183-230.

VAsconcelos, J. L. (1913): Religiões da Lusitânia, III, Lisboa.

Zabaleta Estévez, M. Del Mar (2000): "Hallazgos Numismáticos de los comienzos de Bracara Augusta", [en] Actas do $3^{\circ}$ Congresso de Arqueologia Peninsular VI, Porto, 395-399. 